\title{
Outcomes of cirrhotic patients admitted to the intensive care unit after a successful cardiac arrest resuscitation
}

\author{
Moayed N. Alkblewi, MBBS, Hasan M. Al-Dorzi, MD, Farhan Z. Alenezi, MBBS, Abdulrabman M. Farhat, MBBS, \\ Hani Tamim, PhD, Musharaf Sadat, MBBS, Felwa Bin Humaid, BSc, Yaseen M. Arabi, MD, FCCP.
}

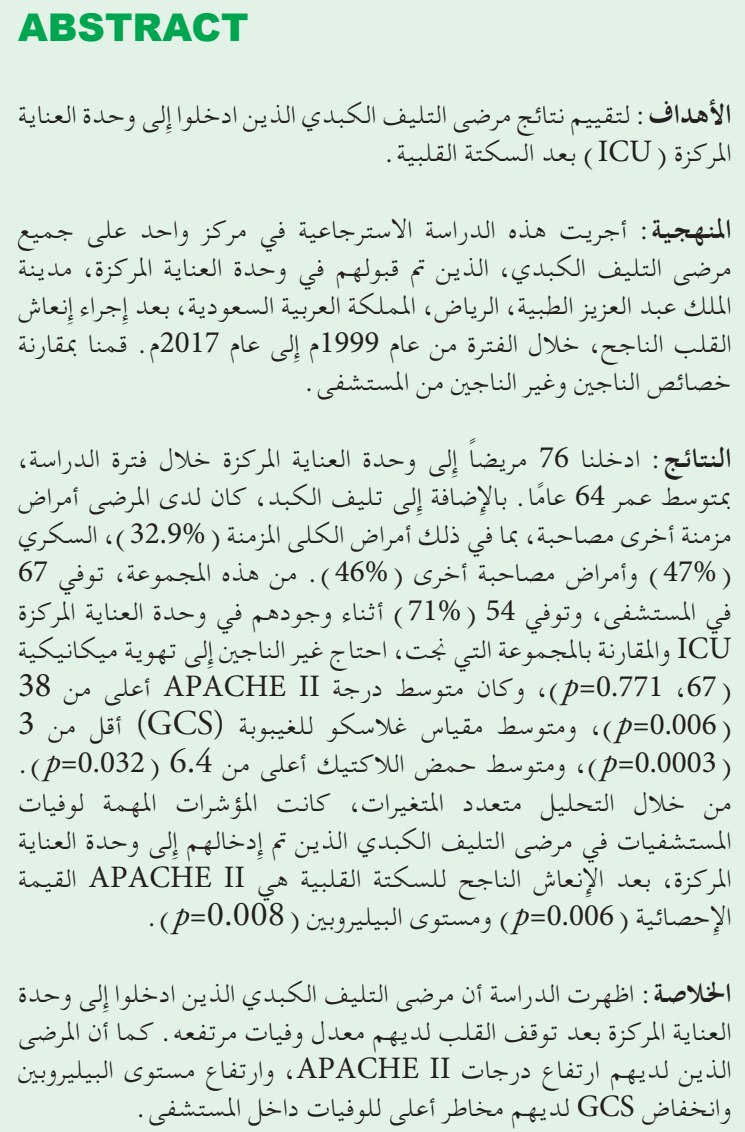

Objectives: To evaluate the outcomes of cirrhotic patients admitted to the intensive care unit (ICU) following cardiac arrest.

Methods: This was a single centre retrospective study of all the cirrhotic patients, admitted to the ICU at King Abdulaziz Medical City, Riyadh, Saudi Arabia, after a successful cardiac arrest resuscitation, from 1999 to 2017. The characteristics of the hospital survivors and non-survivors were compared.

Results: A total of 76 patients were admitted to the ICU during the study period, with a median age of
64 years. In addition to cirrhosis, the patients had other chronic comorbidities, including chronic renal disease $(32.9 \%)$ and diabetes (47\%). Of this group, $67(88.2 \%)$ died in the hospital, and $54(71 \%)$ died while in ICU. Compared to the group who survived, all non-survivors required mechanical ventilation and had a higher median APACHE II score of 38 $(p=0.006)$, a lower median Glasgow coma score (GCS) of $3(p=0.0003)$, and a higher median lactic acid of $6.4 \mathrm{mmol} / \mathrm{L}(p=0.032)$. On multivariable logistic regression analysis, the important predictors of hospital mortality were APACHE II score $(p=0.006)$, bilirubin level $(p=0.008)$ and GCS $(p=0.005)$.

Conclusion: Cirrhotic patients admitted to the ICU following cardiac arrest have high mortality. Patients with higher APACHE II scores, higher bilirubin and lower GCS have higher risk of in-hospital mortality.

Keywords: cirrhosis, ICU, outcome, cardiac arrest, successful resuscitation

Saudi Med J 2021; Vol. 42 (12): 1320-1324 doi: 10.15537/smj.2021.42.12.20210478

From the Department of Emergency Medicine and Critical Care (Alkhlewi); from the Intensive Care Department (Al-Dorzi, Alanazi, Sadat, Bin Humaid, Arabi), King Abdulaziz Medical City, and from the Ministry of National Guard-Health Affairs; from the College of Medicine (Alkhlewi, Al-Dorzi, Alanazi, Sadat, Tamim, Arabi), King Saud bin Abdulaziz University for Health Sciences; from King Abdullah International Medical Research Center (Alkblewi, Al-Dorzi, Alanazi, Farhat, Tamim, Sadat, Humaid, Arabi), Riyadh; from the Faculty of Medicine (Farhat), Sulaiman Alrajhi University, Qassim, Kingdom of Saudi Arabia; and from the Department of Internal Medicine (Tamim), American University of Beirut, Beirut, Lebanon.

Received 5th July 2021. Accepted 18th October 2021.

Address correspondence and reprint request to: Dr. Yaseen Arabi, Chairman, Intensive Care Department, College of Medicine King Saud Bin Abdulaziz University for Health Sciences, Riyadh, Kingdom of Saudi Arabia. E-mail: yaseenarabi@yahoo.com ORCID: https://orcid.org/0000-0001-5735-6241 
C hronic liver disease is prevalent globally. Cirrhosis ${ }_{\text {is }}$ its last stage in which patients present with a diversity of clinical manifestations, presentations, and complications. The World Health Organization (WHO) reported that $46 \%$ of the diseases globally, and $59 \%$ of the global mortality is due to chronic diseases, equating to 35 million deaths. ${ }^{1}$ Of the chronic diseases, chronic liver disease constitutes a large proportion, which increases annually. The United Kingdom's National Statistics reported that liver disease is the fifth most prevalent cause of mortality. ${ }^{2}$ In the United States (US), liver diseases was ranked second in the leading causes of fatalities due to gastrointestinal disorders. ${ }^{3}$ As stated by the WHO in 2018, liver disease in Saudi Arabia was responsible for $3.08 \%$ of the total mortality. ${ }^{4}$ The age-adjusted mortality rate per 100,000 was 20.24 in Saudi Arabia, ranking 71 globally. ${ }^{4}$

The number of patients with liver cirrhosis requiring hospital admission is increasing. ${ }^{5,6}$ Admission is due to various medical complications, in addition to the chronic liver disease, causing high rates of morbidity and mortality. ${ }^{7,8}$ Cardiac arrest (CA) is a catastrophic complication in patients with cirrhosis, which frequently requires admission to ICU. ${ }^{9}$ An estimated 375,000-700,000 patients have CA in Europe and USA annually and receive resuscitation (CPR). ${ }^{10,11}$ Despite the advancements in critical and emergency care, the rates of survival after $\mathrm{CA}$, remain very low, ranging from $14 \%-23 \%$ for in-hospital and $8 \%-16 \%$ for out of hospital CA. ${ }^{12-15}$

Literature related to the outcome of patients with liver cirrhosis, with a successful resuscitation after CA, is limited. Roedl et $\mathrm{al}^{9}$ investigated the outcome of inand out-of-hospital CA survivors with liver cirrhosis. The patients with cirrhosis who survived CA had worse outcome compared to the group without cirrhosis. ${ }^{9}$ Although almost $20 \%$ of the cirrhotic patients survived more than 28 days after the successful CPR, the patients with Child-Turcotte-Pugh $\mathrm{C}$ and advanced acute-on-chronic liver failure did not survive 28 days with good neurological outcome. ${ }^{9}$ The objective of this study was to examine the hospital mortality and other clinical outcomes of cirrhotic patients admitted to the ICU after a successful CA resuscitation.

Disclosure. Authors have no conflict of interests, and the work was not supported or funded by any drug company.
Methods. This was a retrospective study of all the consecutive cirrhotic patients admitted to the ICU at King Abdulaziz Medical City, Riyadh, Saudi Arabia, from 1999-2017 after a successful CA resuscitation. We excluded patients transferred from other hospitals. For patients admitted to the ICU more than once within the same hospitalization, we included the first admission only. The study protocol was approved by the Institutional Review Board, Ministry of National GuardHealth Affairs, Riyadh, Saudi Arabia (IRBC/1816/20).

Data were extracted from the ICU database, which has been maintained prospectively from 1999 to 2017 . The data included variables collected at baseline and follow-up. The baseline variables included age, gender, chronic diseases as defined by the Acute Physiology And Chronic Health Evaluation II (APACHE II system), ${ }^{16}$ mechanical ventilation, vasopressor therapy, bilirubin, Glasgow coma scale (GCS), creatinine, lactic acid, international normalized ratio (INR), and ratio of arterial oxygen partial pressure to fractional inspired oxygen $(\mathrm{PaO} 2 / \mathrm{FiO} 2$ ratio). The primary outcome was hospital mortality, and the secondary outcomes were ICU mortality, ICU and hospital lengths of stay, tracheostomy, and mechanical ventilation duration.

Statistical analysis. The data were analyzed using Statistical Analysis System (SAS), version 9.0 (SAS Institute, CARY, NC, USA). Continuous variables were presented as medians and interquartile ranges and categorical variables as frequencies and percentages. All variables at baseline and follow-up were compared between the group who died or survived at hospital discharge. Categorical variables were compared using Fisher's exact test and continuous variables with Mann-Whitney test. To determine the predictors of hospital mortality for the cirrhotic patients admitted with CA, a multivariable logistic regression analysis was performed adjusting for the following variables, selected on the basis of statistical as well as their clinical significance: age, APACHE II, bilirubin, INR, chronic cardiac disease, vasopressor therapy, mechanical ventilation, lactic acid and $\mathrm{PaO} 2 / \mathrm{FiO} 2$ ratio. The results are reported as odds ratios (OR) and 95\% confidence intervals (CI). A $p$-value of $<0.05$ was considered statistically significant.

Results. A total of 76 cirrhotic patients were admitted to the ICU after a successful CA resuscitation from 1999 to 2017. Of the 76 patients, 67 patients died in hospital (88.2\%) and only 9 survived (11.8\%). The median age was 64 years (Q1, Q3: 57, 73) and $59 \%$ were males. In addition to cirrhosis, patients had other chronic comorbidities, including chronic renal 
disease (32.9\%), chronic cardiac disease (22.4\%), diabetes (47\%), chronic respiratory disease (15\%), and immunocompromised state (9\%). Forty-seven patients $(62 \%)$ were receiving vasopressors and 73 (96\%) were mechanically ventilated on admission. The median APACHE II score was 37 (Q1 [quartile 1], Q3 28.5, 42.0), bilirubin was $63 \mu \mathrm{mol} / \mathrm{L}$ (Q1, Q3: 21, 162), GCS score was 3 (Q1, Q3: 3, 8), creatinine was $195.5 \mu \mathrm{mol} / \mathrm{L}$ (Q1, Q3: 131, 271), lactic acid was $5.8 \mathrm{mmol} / \mathrm{L}(\mathrm{Q} 1, \mathrm{Q} 3: 2.9,10.1)$, INR was 1.7 (Q1, Q3: $1.4,2.7$ ), and the $\mathrm{PaO} 2 / \mathrm{FiO} 2$ ratio was 155 (Q1, Q3: 79, 237) (Table 1).

Compared to the group who survived, the group who died in hospital was more likely to have required mechanical ventilation $(p=0.003)$ and had a higher median APACHE II score of 38 (Q1, Q3: 30, 43, $p=0.006$ ), a lower median GCS of 3 (Q1, Q3: 3, 7) $(p<0.0003)$, and a higher median lactic acid of $6.4 \mathrm{mmol} / \mathrm{L}$ (Q1, Q3: 3.7, 11.5, $p=0.032$ )(Table 1).

Secondary outcomes. Of the cohort, 54 (71\%) died while in ICU. The median ICU length of stay was 2.2 days (Q1, Q3: 0.5, 9.3), the hospital length of stay was 10 days $(\mathrm{Q} 1, \mathrm{Q} 3:$ 4, 30), and the median mechanical ventilation duration was 3 days (Q1, Q3: 1, 10). A minority $(13 \%)$ had a tracheostomy. There were no significant differences in the duration of mechanical ventilation and the length of stay in the ICU and hospital between hospital survivors and nonsurvivors (Table 2).

Table 2 - Outcomes of cirrhotic patients admitted to the ICU after successful cardiac arrest resuscitation between non-survivors and survivors.

\begin{tabular}{|c|c|c|c|c|}
\hline Variable & $\begin{array}{c}\text { All } \\
\mathrm{n}=76\end{array}$ & $\begin{array}{l}\text { Died } \\
\mathrm{n}=67\end{array}$ & $\begin{array}{c}\text { Survived } \\
\mathrm{n}=9\end{array}$ & $P$-value \\
\hline $\begin{array}{l}\text { ICU LOS (days), } \\
\text { median (Q1, Q3) }\end{array}$ & $\begin{array}{l}2.2(0.5 \\
9.3)\end{array}$ & $\begin{array}{c}1.8 \\
(0.5,9.2)\end{array}$ & $\begin{array}{c}3.5(2.5, \\
14.3)\end{array}$ & 0.181 \\
\hline $\begin{array}{l}\text { Hospital LOS (days), } \\
\text { median (Q1, Q3) }\end{array}$ & $10(4,30)$ & $13(3,26)$ & $64(7,380)$ & 0.136 \\
\hline $\begin{array}{l}\text { Mechanical ventilation } \\
\text { duration (days), } \\
\text { median (Q1, Q3) }\end{array}$ & $3(1,10)$ & $3(1,9)$ & $2(0,17)$ & 0.771 \\
\hline Tracheostomy, n (\%) & $10(13)$ & $7(11)$ & $3(33)$ & 0.057 \\
\hline \multicolumn{5}{|c|}{$\begin{array}{l}\text { The denominator is the total number of subjects in the group. For } \\
\text { continuous variables, Mann-Whitney test is used to calculate the } p \text {-value. } \\
\text { For categorical variables, Fisher's exact test is used to calculate the } p \text {-value } \\
\text { ICU: intensive care unit, LOS: length of stay, Q: quartile }\end{array}$} \\
\hline
\end{tabular}

Table 1 - Comparison of baseline characteristics of cirrhotic patients admitted to the ICU after successful cardiac arrest resuscitation between non-survivors and survivors.

\begin{tabular}{|c|c|c|c|c|}
\hline Variable & $\underset{n=76}{\text { All }}$ & $\begin{array}{l}\text { Died } \\
n=67\end{array}$ & $\begin{array}{c}\text { Survived } \\
\mathrm{n}=9\end{array}$ & $P$-value \\
\hline Age (yrs), median (Q1, Q3) & $64(57,73)$ & $64(54,73)$ & $67(59,72)$ & 0.625 \\
\hline Male gender, $\mathrm{n}(\%)$ & $45(59)$ & $39(58)$ & $6(67)$ & 0.628 \\
\hline Diabetes, n (\%) & $36(47)$ & $32(48)$ & $4(44)$ & 0.852 \\
\hline \multicolumn{5}{|l|}{ Other chronic Diseases, $n$ (\%) } \\
\hline Chronic respiratory & $11(15)$ & $8(12)$ & $3(33)$ & 0.087 \\
\hline Chronic renal & $25(32.9)$ & $23(34.3)$ & $2(22)$ & 0.468 \\
\hline Immunocompromised & $7(9)$ & $5(8)$ & $2(22)$ & 0.151 \\
\hline Chronic cardiac & $17(22.4)$ & $12(17.9)$ & $5(55.56)$ & 0.007 \\
\hline GCS on ICU admission, median (Q1, Q3) & $3(3,8)$ & $3(3,7)$ & $10(9,15)$ & 0.0003 \\
\hline Mechanical ventilation, $\mathrm{n}(\%)$ & $73(96)$ & $67(100)$ & $6(66.7)$ & 0.003 \\
\hline Vasopressors, n (\%) & $47(62)$ & $42(63)$ & $5(56)$ & 0.679 \\
\hline APACHE II, median (Q1, Q3) & $37(28.5,42)$ & $38(30,43)$ & $24(15,29)$ & 0.006 \\
\hline \multicolumn{5}{|l|}{ Laboratory findings in the first 24 hours } \\
\hline Bilirubin $(\mu \mathrm{mol} / \mathrm{L})$, median $(\mathrm{Q} 1, \mathrm{Q} 3)$ & $63(21,162)$ & $65(29,191)$ & $17.5(10.5,26.5)$ & 0.008 \\
\hline Creatinine $(\mu \mathrm{mol} / \mathrm{L})$, median $(\mathrm{Q} 1, \mathrm{Q} 3)$ & $195.5(131,271)$ & $199(141,283)$ & $167(74,215)$ & 0.150 \\
\hline Lactic acid mmol/L, median (Q1, Q3) & $5.8(2.9,10.1)$ & $6.4(3.7,11.5)$ & $2.9(2,4.7)$ & 0.032 \\
\hline INR, median (Q1, Q3) & $1.7(1.4,2.7)$ & $1.75(1.40,2.70)$ & $1.5(1.3,2.2)$ & 0.715 \\
\hline $\mathrm{PaO} 2 /$ Fio2 ratio, median $(\mathrm{Q} 1, \mathrm{Q} 3)$ & $155(79,237)$ & $150(74,230)$ & $214(128,238)$ & 0.425 \\
\hline \multicolumn{5}{|c|}{$\begin{array}{l}\text { For categorical variables, Fisher's exact test is used to calculate the } p \text {-value. For continuous variables, Mann-Whitney test is } \\
\text { used to calculate the } p \text {-value. For all percentages, the denominator is the total number of subjects in the group. } \\
\text { APACHEII: Acute Physiology And Chronic Health Evaluation II, GCS: Glasgow coma score, INR: internal normalized } \\
\text { ratio, } \mathrm{PaO} 2 / \mathrm{FiO} 2 \text { ratio: the ratio of the partial pressure of oxygen to the fraction of inspired oxygen, Q1: first quartile, Q3: } \\
\text { third quartile }\end{array}$} \\
\hline
\end{tabular}


Table 3 - Logistic regression analysis to identify independent predictors of in-hospital mortality among cirrhotic patients admitted to the intensive care unit after successful cardiac arrest resuscitation.

\begin{tabular}{lccc}
\hline Variables & OR & $95 \%$ CI & $P$-value \\
\hline Age (per 1-year increase) & 0.99 & $0.93-1.06$ & 0.830 \\
APACHE II (per 1-unit & 1.21 & $1.06-1.38$ & 0.005 \\
increase) & & & \\
Bilirubin (per 1-unit increase) & 1.04 & $1.01-1.07$ & 0.022 \\
Vasopressor & 13.69 & $0.62-301.91$ & 0.097 \\
GCS & 0.66 & $0.50-0.88$ & 0.005 \\
\hline
\end{tabular}

GSC: Glasgow coma scale, OR: odds ratio, CI: confidence interval

Multivariate analysis to determine the predictors of hospital mortality. The multivariable logistic regression analysis demonstrated that the important predictors of hospital mortality for the cirrhotic patients admitted to the ICU after a successful CA resuscitation were APACHE II score (OR 1.21, 95\% CI 1.06 to 1.38 , $p=0.005$ ), the level of bilirubin (OR 1.02, 95\% CI 1.00 to $1.05, p=0.02$ ) and GCS (OR $0.66,95 \%$ CI 0.50 to $0.88, p=0.005$ ) (Table 3 ).

Discussion. In this study, we analyzed 76 cirrhotic patients admitted to ICU following a successful CA resuscitation. We found that these patients had high mortality. Patients with higher APACHE II scores, higher bilirubin and lower GCS had higher risk of in-hospital mortality.

The prevalence of cirrhosis in the ICU ranges from $4 \%$ to $7 \%$ of critically ill patients. ${ }^{17,18}$ We report a hospital mortality of $88.2 \%$ for patients with cirrhosis who had a CA. Another study reported a similar mortality rate of $79 \%$ in cirrhotic patients, compared to $50 \%$ in non-cirrhotic patients, admitted to ICU after CA. ${ }^{9}$ In addition, they reported that the group with liver cirrhosis who survived had poor neurological outcomes. This high mortality rate could be explained by high rates of non-cardiac causes of CA, the prevalent comorbidities and high rate of non-shockable rhythms in the group with cirrhosis. There is a slight difference in the mortality rates between the current study and that of Roedl et $\mathrm{al}^{9}$. The factors that may have resulted in this difference include risk factors of liver cirrhosis in Saudi Arabia. Most of the patients with liver cirrhosis in Saudi Arabia are due to a complication of hepatitis $C$ and hepatitis $\mathrm{B}$, which have poorer prognosis. ${ }^{19}$ In contrast, alcoholic liver disease is more common than viral hepatitis as a cause of liver cirrhosis in Western countries, which have a relatively better prognosis compared to viral hepatitis. ${ }^{20}$ Cirrhotic patients with cardiac diseases can be successfully resuscitated after CA, however, they have a significant decrease in the functional outcome and a significant chance of dying after the resuscitation. The current study and literature support this statement. ${ }^{7,21}$ The high APACHE II scores indicate severe liver disease; hence, the significant association with an increased mortality rate. The median score for the group with the worst outcome was 38 , compared to 24 in the group who survived. Several studies reported a similar negative outcome for patients with severe liver disease, indicated in the current study by the high APACHE II scores. ${ }^{7,22}$ Roedl et al ${ }^{9}$ described several possible predictors, including witnessing of the $\mathrm{CA}$ and the period of ischemia. They attributed the worse outcomes following CA to the severity of the liver disease. Literature highlights post-CA syndrome, in which an exacerbation of liver disease is expected, and as a consequence, an increased mortality rate. ${ }^{22,23}$

Our study indicated that the use of mechanical ventilation, low GCS score and high levels of lactic acid were associated with increased mortality. Of the 73 patients who were mechanically ventilated, 67 died and 6 survived. The group with worse outcomes had a median GCS of 3, compared to the group who survived with a median of 10 . Similarly, patients with higher lactate levels had worse outcomes (median lactate of those who died was $6.4 \mathrm{mmol} / \mathrm{L}$ compared to $2.9 \mathrm{mmol} / \mathrm{l}$ for the group who survived).

Study limitations. Although the sample size of the current study was 76 , which is relatively high, a larger sample size will result in more precise data and better interpretation of findings. Prospective multicentric studies and data containing more details and clinical scores such as the Child-Pugh score are required.

In conclusion, cirrhotic patients with CA have poor outcomes. Patients with higher APACHE II scores, higher bilirubin and lower GCS have higher risk of in-hospital mortality.

Acknowledgment. The authors gratefully acknowledge King Abdullah International Medical Research Center for English language editing.

\section{References}

1. Murray CJ, Lopez AD. Evidence-based health policy - Lessons from the global burden of disease study. Science 1996; 274: 5288.

2. GOV.UK. Research and statistics. Please include the title of thr article. [Updated 2020; Accessed 2021 February 20]. Available from: http://www.statistics.gov.uk/

3. Everhart JE, Ruhl CE. Burden of digestive diseases in the United States part III: liver, biliary tract, and pancreas. Gastroenterology 2009; 136: 1134-1144. 
4. World Life Expectancy. Liver Disease in Saudi Arabia. [Updated 2020 March; Accessed 2021 Feb 20]. Available from: https:// www.worldlifeexpectancy.com/saudi-arabia-liver-disease

5. Thomson SJ, Westlake S, Rahman TM, Cowan ML, Majeed A, Maxwell JD, et al. Chronic liver disease - an increasing problem: A study of hospital admission and mortality rates in England, 1979-2005, with particular reference to alcoholic liver disease. Alcohol Alcohol 2008; 43; 416-422.

6. McPhail MJW, Parrott F, Wendon JA, Harrison DA, Rowan KA, Bernal W. Incidence and outcomes for patients with cirrhosis admitted to the United Kingdom critical care units. Crit Care Med 2018; 46: 705-712.

7. McPhail MJW, Shawcross DL, Abeles RD, Chang A, Patel V, Lee $\mathrm{GH}$, et al. Increased survival for patients with cirrhosis and organ failure in liver intensive care and validation of the chronic liver failure-sequential organ failure scoring system. Clin Gastroenterol Hepatol 2015; 13: 1353-1360.

8. Cholongitas E, Senzolo M, Patch D, Kwong K, Nikolopoulou V, Leandro G, et al. Risk factors, sequential organ failure assessment and model for end-stage liver disease scores for predicting short term mortality in cirrhotic patients admitted to intensive care unit. Aliment Pharmacol Ther 2006; 23: 83-93.

9. Roedl K, Wallmüller C, Drolz A, Horvatits T, Rutter K, Spiel A, et al. Outcome of in- and out-of-hospital cardiac arrest survivors with liver cirrhosis. Ann Intensive Care 2017; 7: 103.

10. Mozaffarian D, Benjamin EJ, Go AS, Arnett DK, Blaha MJ, Cushman M, et al. Heart disease and stroke statistics2016 update a report from the American Heart Association. Circulation 2016; 133: e38-e360.

11. Berdowski J, Berg RA, Tijssen JGP, Koster RW. Global incidences of out-of-hospital cardiac arrest and survival rates: Systematic review of 67 prospective studies. Resuscitation 2010; 81: 1479-1487.

12. Atwood C, Eisenberg MS, Herlitz J, Rea TD. Incidence of EMS-treated out-of-hospital cardiac arrest in Europe. Resuscitation 2005; 67: 75-80.

13. Nichol G, Thomas E, Callaway CW, Hedges J, Powell JL, Aufderheide TP, et al. Regional variation in out-of-hospital cardiac arrest incidence and outcome. JAMA 2008; 300: 1423-31.
14. Peberdy MA, Kaye W, Ornato JP, Larkin GL, Nadkarni V, Mancini ME, et al. Cardiopulmonary resuscitation of adults in the hospital: A report of 14720 cardiac arrests from the National Registry of Cardiopulmonary Resuscitation. Resuscitation 2003; 58: 297-308.

15. Meaney PA, Nadkarni VM, Kern KB, Indik JH, Halperin HR, Berg RA. Rhythms and outcomes of adult in-hospital cardiac arrest. Crit Care Med 2010; 38: 101-108.

16. Knaus WA, Draper EA, Wagner DP, Zimmerman JE. APACHE II: A severity of disease classification system. Crit Care Med 1985; 13: 818-829.

17. Piton G, Chaignat C, Giabicani M, Cervoni JP, Tamion F, Weiss E, et al. Prognosis of cirrhotic patients admitted to the general ICU. Ann Intensive Care 2016; 6: 94.

18. Fuhrmann V, Kneidinger N, Herkner H, Heinz G, Nikfardjam M, Bojic A, et al. Impact of hypoxic hepatitis on mortality in the intensive care unit. Intensive Care Med 2011; 37: 1302-1310.

19. Fashir B, Sivasubramaniam V, Momen S Al, Assaf H. Pattern of liver disease in a Saudi patient population: a decade of experience at security forces hospital, Riyadh, KSA. Saudi J Gastroenterol 1996; 2: 50-52.

20. Pimpin L, Cortez-Pinto H, Negro F, Corbould E, Lazarus JV, Webber L, et al. Burden of liver disease in Europe: Epidemiology and analysis of risk factors to identify prevention policies. $J$ Hepatol 2018; 69: 718-735.

21. Moreau R, Jalan R, Gines P, Pavesi M, Angeli P, Cordoba J, et al. Acute-on-chronic liver failure is a distinct syndrome that develops in patients with acute decompensation of cirrhosis. Gastroenterology 2013; 144: 1426-1437, 1437.e1-e9.

22. Drolz A, Horvatits T, Roedl K, Rutter K, Staufer K, Kneidinger $\mathrm{N}$, et al. Coagulation parameters and major bleeding in critically ill patients with cirrhosis. Hepatology 2016; 64: 556-568.

23. Neumar RW, Nolan JP, Adrie C, Aibiki M, Berg RA, Böttiger BW, et al. Post-cardiac arrest syndrome: Epidemiology, pathophysiology, treatment, and prognostication a consensus statement from the International Liaison Committee on Resuscitation. Circulation 2008; 118: 2452-2483. 